\title{
Necrotizing fasciitis after intramuscular injection
}

\section{Fasceite necrotizante após aplicação de injeção intramuscular}

\author{
Gustavo Steffen Alvarez \\ Evandro José Siqueira ${ }^{2}$ \\ Milton Paulo de Oliveira ${ }^{3}$ \\ Pedro Djacir Escobar \\ MARTINS $^{4}$
}

This study was performed at the Department of Plastic Surgery at Hospital São Lucas da Pontifícia Universidade Católica do Rio Grande do Sul/St. Luke's Hospital Catholic University of Rio Grande do Sul (PUC-RS), Porto Alegre, RS, Brazil

Submitted to SGP (Sistema de Gestão de Publicações/Manager Publications System) of RBCP (Revista Brasileira de Cirurgia Plástica/Brazilian Journal of Plastic Surgery).

Article received: May 25, 2011 Article accepted: October 18, 2011

\begin{abstract}
We report the case of a 1-year-old boy who developed necrotizing fasciitis of the groin and thighs after intramuscular injection of metoclopramide. We discuss and highlight the key aspects of diagnosis and treatment of this disease, with an emphasis on the importance of early identification of factors that can contribute significantly to improved survival.
\end{abstract}

Keywords: Fasciitis. Debridement. Metoclopramide.

\section{RESUMO}

É relatado o caso de um paciente do sexo masculino, de 1 ano e 2 meses, apresentando quadro de fasceíte necrotizante comprometendo região inguinal e coxas após injeção intramuscular de metoclopramida. Neste artigo, são discutidos e apontados os aspectos fundamentais do diagnóstico e tratamento da doença, ressaltando a importância da identificação precoce dos fatores que possam contribuir significativamente para melhora da sobrevida.

Descritores: Fasciite. Desbridamento. Metoclopramida.

\section{INTRODUCTION}

Necrotizing fasciitis is characterized by a severe infection involving the subcutaneous tissue and superficial fascia ${ }^{1}$. Despite advances in the field of critical care, mortality for this disease remains very high $(15 \%-50 \%)$, making early diagnosis and suitable therapy crucial ${ }^{1}$. This fulminant disease is characterized by an infection, usually polymicrobial, caused by necrotoxin-producing bacteria (beta-hemolytic group A estreptococcus, Staphylococcus aureus, and anaerobes). The synergism between these bacteria is responsible for the fulminant course of the disease, and surgical exploration is important for both diagnosis and therapy ${ }^{2}$. It is not always easy to identify this disease in its early stages, and it may be confused with simple infections such as cellulitis ${ }^{3}$.

Plastic surgeons often have to evaluate cases of soft tissue infection in various forms. Therefore, it is crucial to understand the main causes of these infections, as well as the early signs and symptoms that may indicate the presence of a more severe disease process than initially suspected.

We report the case of a pediatric patient who presented with necrotizing fasciitis in the lower limb after intramuscular injection of metoclopramide. We discuss and

1. Plastic surgeon, associate member of the Sociedade Brasileira de Cirurgia Plástica/Brazilian Society of Plastic Surgery (SBCP), doctoral Student in Medicine and Health Sciences at Pontifícia Universidade Católica do Rio Grande do Sul/Catholic University of Rio Grande do Sul (PUC-RS), Porto Alegre, RS, Brazil.

2. Plastic surgeon, associate member of the SBCP, Porto Alegre, RS, Brazil.

3. Plastic surgeon, full member of the SBCP, preceptor of the Plastic Surgery Service of the Hospital São Lucas da Pontifícia Universidade Católica do Rio Grande do Sul/St. Luke's Hospital Catholic University of Rio Grande do Sul (HSL-PUC-RS), Porto Alegre, RS, Brazil.

4. Plastic surgeon, full member of the SBCP, regent of the Plastic Surgery Service of the HSL-PUCRS, Porto Alegre, RS, Brazil. 
highlight the main aspects of the disease; the findings of this case indicate that soft tissue infections should not be underestimated.

\section{CASE REPORT}

A previously healthy Caucasian boy aged 1 year and 2 months presented with fever and vomiting. He was treated in a tertiary hospital in the city of Porto Alegre (RS, Brazil), where he received an intramuscular injection of metoclopramide in the left thigh and was subsequently released from the hospital. Two days later, he was taken to the emergency room of St. Luke's Hospital of the Catholic University of Rio Grande do Sul (PUCRS) with a small hematoma in the left inguinal region.

The next day, he showed a progressive worsening of the hematoma with extension to the anterior region of the left thigh and the left inguinal region as well as to the posterior right thigh. In association with the cutaneous progression, there was concomitant worsening of laboratory and clinical symptoms, and he was transferred to the intensive care unit (ICU).

He developed septic shock, which was accompanied by extensive skin necrosis of the left inguinal region, the anterior part of the left thigh, and the back of the right thigh.

After clinical stabilization of the patient, the plastic surgery team performed surgical debridement. There was evidence of dermal necrosis, with friable, grayish subcutaneous tissue, necrosis of perforating vessels, and purulent and malodorous serosanguineous discharge.

Two other surgical procedures were performed for debridement and reconstruction. Subsequently, the surgical site was covered with skin grafts. Partial transposition and advancement flaps were placed on the posterior side, and right thigh flap transposition (rhomboid) was performed in the left inguinal region to provide appropriate protection to the femoral vessels.

The patient had a favorable outcome and was discharged after 80 days of hospitalization.

\section{DISCUSSION}

Necrotizing fasciitis is one of the most severe soft tissue infections, having high mortality rates even in highly qualified centers ${ }^{1}$. All researchers are unanimous in asserting the importance of early diagnosis and treatment for improving the current survival rates ${ }^{3-5}$. The 2 main pitfalls with these cases are faulty diagnosis and inadequate surgical debridement $^{5}$.

Necrotizing fasciitis is defined as a primary infection of the superficial fascia; this infection extends subcutaneously and is mediated by necrotoxins, primarily the enzyme hyaluronidase. This leads to liquefactive necrosis of the superficial fascia with thrombosis of the perforating vessels of the skin and consequent ischemia. This condition can be caused by skin lesions both directly and through the hematogenic pathway ${ }^{5,6}$.

Adult patients with signs of polymicrobial necrotizing fasciitis usually have concomitant chronic debilitating diseases such as diabetes, kidney failure, or alcoholism ${ }^{5}$. However, in children, this infection is usually caused by Streptococcus pyogenes (group A), which is the primary causative agent worldwide ${ }^{4,5}$. These 2 types of necrotizing fasciitis are classified as type I (polymicrobial involving anaerobes and non-group A streptococci) and type II (monomicrobial caused by group A streptococci) ${ }^{7}$.

The main entrance sites are sites of previous trauma and skin lesions, with the initial site of attack, in descending order of frequency, being typically in the abdomen, buttock, or hips ${ }^{3,8}$.

An understanding of the pathophysiology of the disease as well as of the mechanisms that cause it is essential for early identification of cases. Retrospective studies indicate that up to $85 \%$ of cases are diagnosed late and are confused with cellulitis ${ }^{9}$. Because the infection starts in the deep fascia, specific symptoms such as blisters and crackles are uncommon $(<40 \% \text { of cases })^{8}$. Early symptoms and signs of the disease are edema and erythema ( $78 \%-100 \%$ of cases), significant pain $(83 \%)$, and fever $(83 \%)$. With progression of the disease, the symptoms become more prominent, with blistering, a crusting necrotic appearance of the skin, formation of a gray secretion derived from the subcutaneous layer, localized loss of sensation, and crepitation ${ }^{3,5,8}$. To distinguish early stages of necrotizing fasciitis from cellulitis, a study comparing symptoms and signs between cellulitis and fasciitis concluded that patients with fasciitis often showed a generalized erythematous rash and a more toxic appearance ${ }^{5}$. Furthermore, low platelet counts were observed in patients with necrotizing fasciitis. Pain that appears disproportionate to the findings of physical examination should also be suggestive of an early stage of necrotizing fasciitis ${ }^{5}$.

The 2 most commonly reported causal factors in pediatric patients are chickenpox lesions and intramuscular injections ${ }^{3}$. The relationship between necrotizing infections and intramuscular injection of anti-inflammatory drugs is widely recognized ${ }^{10}$. No direct correlation has been described between metoclopramide and the development of fasciitis. Therefore, in the present case, the most important causal factor for the development of the infection was probably the intramuscular injection, which provided an entry point for Streptococcus pyogenes, and not the metoclopramide itself. Additionally, the patient had bilateral involvement, and not only at the puncture site. Studies on other such similar cases are necessary to elucidate any relationship between metoclopramide and soft tissue infections. 
Some key issues in the management of these patients should be emphasized. A high index of suspicion, early diagnosis, aggressive surgical exploration and debridement, antibiotics, and ICU support are key factors in successful management of these patients. In cases with an unconfirmed diagnosis, the diagnosis can be based on inspection of frozen-section biopsy specimens obtained through a small incision under local anesthesia ${ }^{1,8}$. For patients in early stages of fasciitis, debridement should be considered as soon as the margins of the necrotic lesion are clearly defined; in later stages, debridement should be performed after the patient is clinically stable ${ }^{4}$. This practice reduces the need for blood transfusions, because of thrombosis of perforating vessels, and reduces surgical trauma in patients who are already metabolically compromised ${ }^{4,9}$. The lesion must be covered with skin (mostly partial skin grafts) as

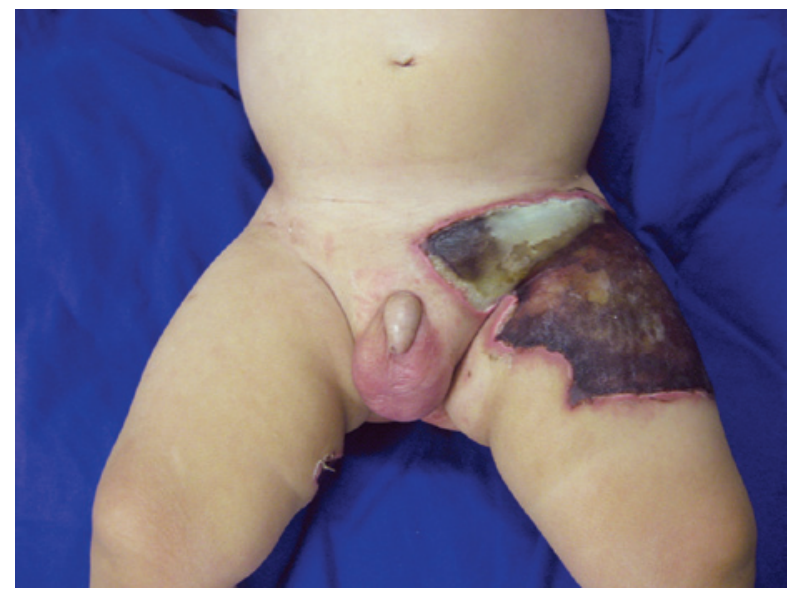

Figure 1 - Preoperative appearance showing extensive dermal necrosis in the inguinal region and base of the left thigh.

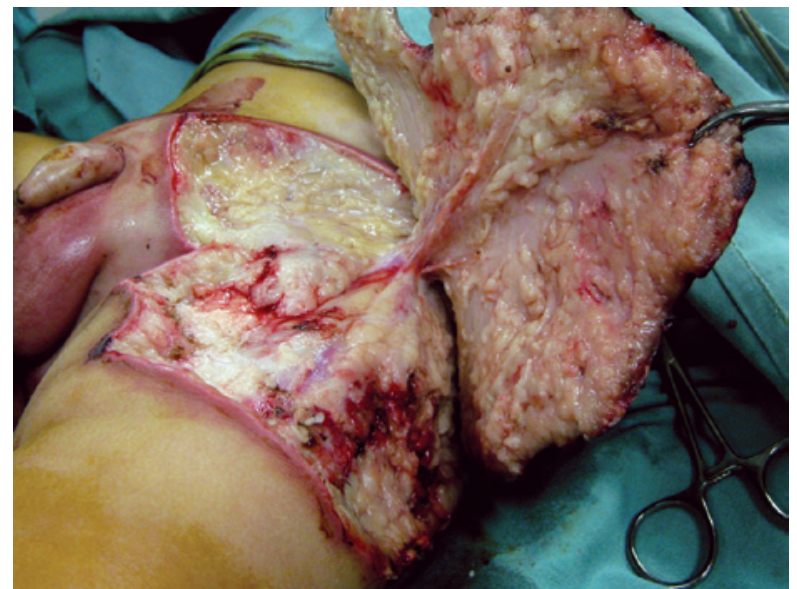

Figure 2 - Intraoperative appearance showing subcutaneous tissue with grayish coloration, serosanguinous purulent fetid secretion, and necrosis of perforating vessels and the underlying fascia. soon as the recipient bed is in an appropriate condition. This reduces the loss of fluid, electrolytes, and proteins, as well as the rate of reinfection and mortality ${ }^{5,8}$.

Figures 1 to 5 illustrate the case reported.

The findings of the present case highlight the importance of early diagnosis and correct treatment of necrotizing fasciitis in order to ensure patient survival.

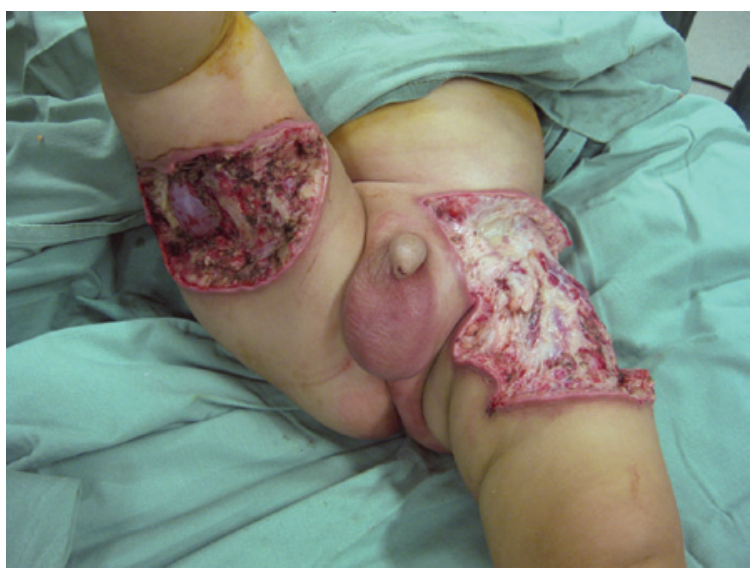

Figure 3 - Final appearance after surgical debridement. 2 more debridement procedures were needed to ensure a receptive bed for the cutaneous coverage.

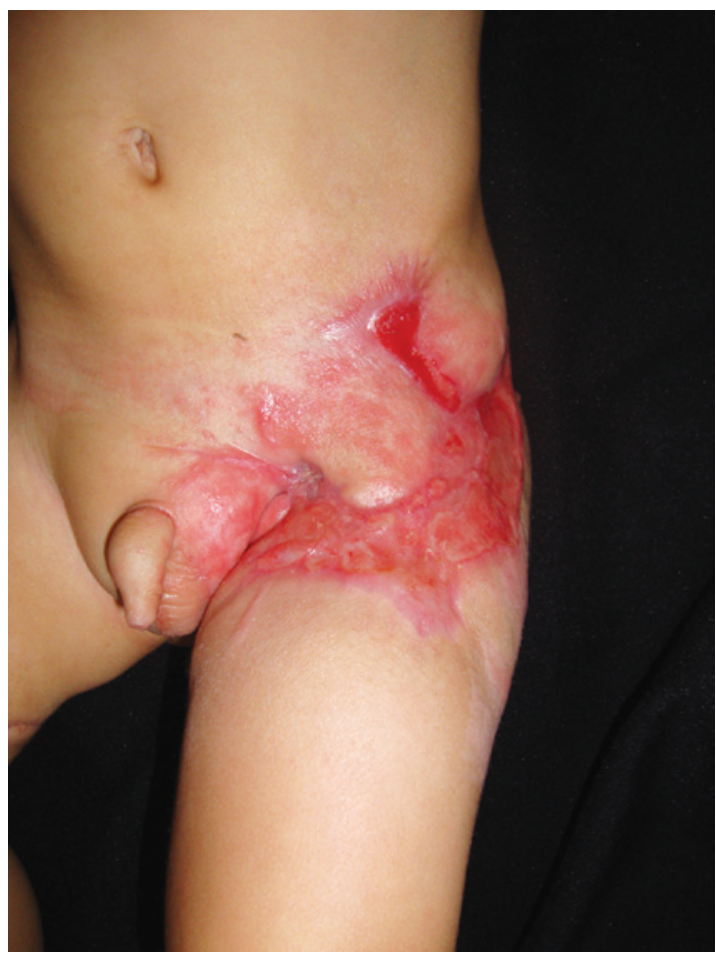

Figure 4 - Three-month postoperative appearance after grafting partial skin and use of Limberg flap to protect the femoral vessels. 

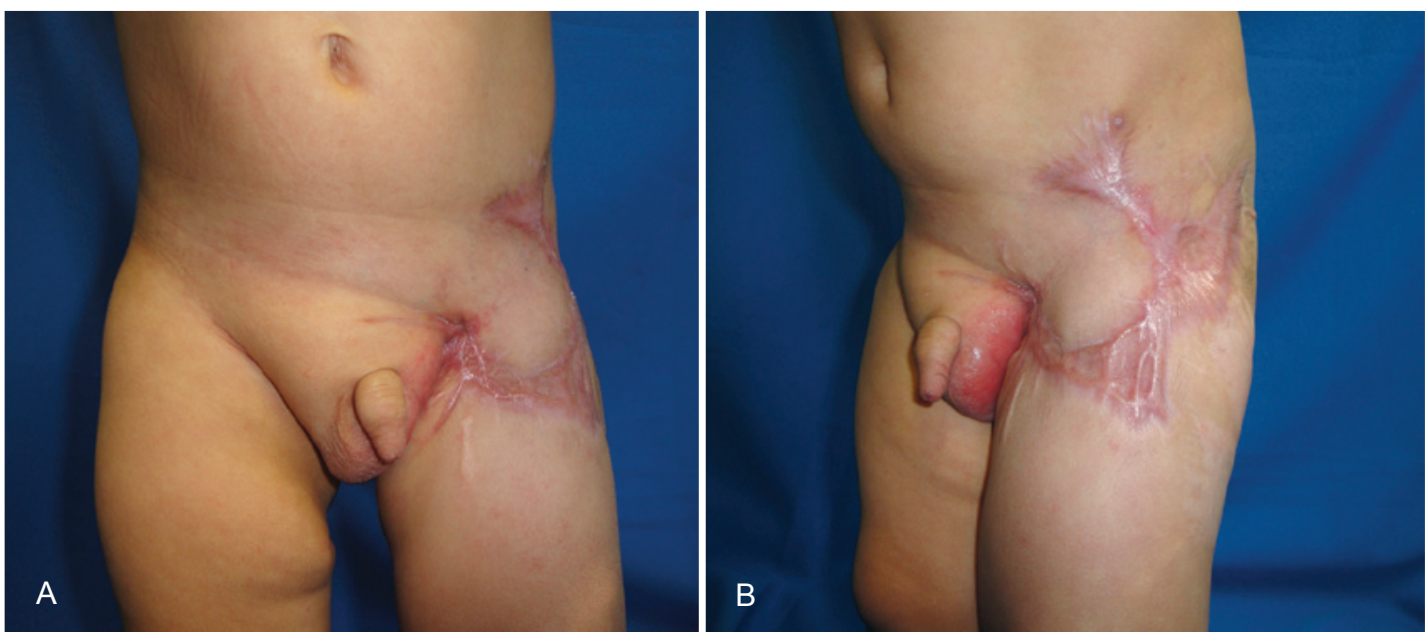

Figure $\mathbf{5}$ - Six-month postoperative appearance. In $\boldsymbol{A}$, frontal view. In $\boldsymbol{B}$, oblique view.

\section{REFERENCES}

1. Elliott D, Kufera JA, Myers RA. The microbiology of necrotizing soft tissue infections. Am J Surg. 2000;179(5):361-6.

2. Cazaes RS, Schettino AM, Ribeiro DSM, Silva PRS, Campos RB. Desbridamento e reconstrução cirúrgica do tronco após trauma. Rev Soc Bras Cir Plást. 2007;22(4):269-73.

3. Fustes-Morales A, Gutierrez-Castrellon P, Duran-Mckinster C, OrozcoCovarrubias L, Tamayo-Sanchez L, Ruiz-Maldonado R. Necrotizing fasciitis: report of 39 pediatric cases. Arch Dermatol. 2002;138(7):893-9.

4. Wakhlu A, Chaudhary A, Tandon RK, Wakhlu AK. Conservative management of necrotizing fasciitis in children. J Pediatr Surg. 2006; 41(6):1144-8.

5. Cheung JP, Fung B, Tang WM, Ip WY. A review of necrotising fasciitis in the extremities. Hong Kong Med J. 2009;15(1):44-52.
6. El-Khatib HA. V-Y fasciocutaneous pudendal thigh flap for repair of perineum and genital region after necrotizing fasciitis: modification and new indication. Ann Plast Surg. 2002;48(4):370-5.

7. Hassell M, Fagan P, Carson P, Currie BJ. Streptococcal necrotising fasciitis from diverse strains of Streptococcus pyogenes in tropical northern Australia: case series and comparison with the literature. BMC Infect Dis. 2004;4(1):60.

8. Cunningham JD, Silver L, Rudikoff D. Necrotizing fasciitis: a plea for early diagnosis and treatment. Mt Sinai J Med. 2001;68(4-5):253-61.

9. Bingöl-Koloğlu M, Yıldız RV, Alper B, Yağmurlu A, Çiftçi E, Gökçora $\mathrm{IH}$, et al. Necrotizing fasciitis in children: diagnostic and therapeutic aspects. J Pediatr Surg. 2007;42(11):1892-7.

10. Rygnestad T, Kvam AM. Streptococcal myositis and tissue necrosis with intramuscular administration of diclofenac (Voltaren). Acta Anaesthesiol Scand. 1995;39(8):1128-30.

\section{Correspondence to:}

Gustavo Steffen Alvarez

Av. Ipiranga, 6.690 - cj. 520 - Jardim Botânico - Porto Alegre, RS, Brazil - CEP 90610-000

E-mail: contato@gustavoalvarez.com.br 